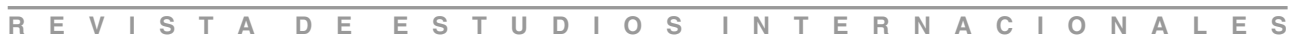

\title{
La política del enfrentamiento: la Intifada, entre violencia y negociaciones
}

\author{
Mario Snajder
}

Desde fines de septiembre del 2000, israelies y palestinos se enfrentan en una nueva secuencia de violencia, matizada periódicamente por intentos de establecer un cese de fuego y negociar una salida del enfrentamiento, como prólogo a un posible retorno a negociaciones de paz. Ríos de tinta se han vertido sobre esta secuencia del conflicto palestino-israelí y las imágenes comunicadas a través de la prensa electrónica han generado muchas opiniones, sin que, en general, se haga demasiado hincapié en el análisis y la comprensión de los factores que integran el problema. En estas páginas, intentaremos presentar una visión crítica y analítica de los hechos, aportando elementos que quizás contribuyan a una mejor comprensión de los procesos que vive esta parte del conflicto del Medio Oriente. El punto de partida de los enfrentamientos denominados Intifada Armada o Intifada al Aqsa se encuentra en la visita de Ariel Sharon, entonces jefe de la oposición al gobierno -líder del Likud-en el parlamento israelí-Knesset-al Monte del Templo-Haram al Shariff, el 28 de septiembre del 2000. Esta visita, percibida por núcleos palestinos como una provocación, fue la chispa que encendió la ola de disturbios que se transforma en el enfrentamiento continuo entre israelies y palestinos, a partir de esa fecha.

Aunque es cierto que la visita de Ariel Sharon al Monte del Templo fue coordinada de antemano con los personeros de seguridad de la Autoridad Palestina, quienes aseguraron que era factible si se mantenía como un hecho restringido al derecho israelí de visitar la zona sacra para el Islam, la interpretación popular, alimentada por la agitación de círculos religiosos islámicos extremistas, fue distinta. Las manifestaciones que sucedieron a la visita tomaron rápidamente el carácter de rebelión popular palestina contra Israel. 


\section{¿GUERRA DE RELIGIÓN?}

1 quí hay que agregar un elemento muy importante que identifica esta ronda de violencia. Si bien el conflicto es definido como intercomunitario hasta $1948 \mathrm{y}$, desde el establecimiento de Israel como Estado soberano, como internacional, hay que tener en cuenta que incluía desde sus inicios un componente religioso.

\section{En el medio Oriente, el componente religioso de la modernidad política se convirtió en uno de los factores decisivos de la política.}

Tenemos que tomar en cuenta que ya a partir de los años veinte, el componente religioso de la modernidad política en el Medio Oriente se convierte en uno de los factores decisivos de la política en las diversas áreas de la zona. En 1929, el Sheik Hassan el Banna funda en Ismailia la Hermandad Musulmana, cuya influencia se hace sentir más allá de las fronteras de Egipto hasta el día de hoy y que, desde entonces, no deja de competir por el poder en su propio país ${ }^{1}$. Por otro lado, Haj Amin el Husseini, hijo de una de las principales familias árabes de Jerusalem, fue nombrado Gran Mufti de esta ciudad por las autoridades británicas en 1921 y ele- gido líder del Supremo Consejo Musulmán Palestino en 1922. Durante los años veinte se convierte en la principal autoridad política de los árabes palestinos, elaborando ideología y políticas que mezclan elementos religiosos musulmanes de rechazo a la modernidad, representada por el Mandato Británico, así como por la presencia sionista en Palestina. Más adelante dirigirá la huelga general y revuelta palestinas (1936-1939), en los mismos términos, en forma cada vez más acentuada y se aliará al fascismo italiano y al nazismo alemán en la II Guerra Mundial, sufriendo un rápido eclipse político tras la derrota palestina en $1948^{2}$.

La mención de al Banna y al Husseini como líderes que combinan legitimidad y autoridad de carácter tanto social como político y religioso sirve para reflejar parte de los dilemas de modernización política de un Medio Oriente en el cual los modelos occidentales de Estados dinásticos modernos y Estados-nación republicanos fueron implantados con mucha rapidez, sobre sociedades básicamente tradicionales en las que la principal fuente de autoridad y legitimidad seguía siendo la religión. De aquí que no debamos extrañarnos cuando frente a procesos de crisis, los elementos religiosos, mezclados con los de modernidad occidental, se articulan proponiendo soluciones mal definidas, desde el punto de vista conceptual, como fundamentalistas y que se describen me-

${ }^{1}$ Vease George Lenczowski. The Middle East in World Affairs, Ithaca and London, Cornell University Press, 1974, $4^{\text {th }}$ edition, págs. 512-513.

${ }^{2}$ La mejor biografía política de al Husseini es la de Zvi Elpeleg, The grand mufti: Haj Amin alHusseini, founder of the Palestinian national movement, Londres, F. Cass, 1993. 
jor como expresiones del Islam Radical o extremismo islámico ${ }^{3}$.

Sin entrar en un análisis detallado, señalaremos sólo algunos hitos de la centralización del Islam Radical en la política del conflicto israelí-palestino. En la parte palestina, a partir de 1979 -período en que se establece la República Islámica en Irány especialmente desde el comienzo de la primera Intifada, a fines de 1987, tal componente religioso del conflicto fue adquiriendo mayor importancia. Los incidentes masivos provocados en septiembre de 1996, tras la apertura de un túnel de la época herodiana a lo largo del Muro de los Lamentos (que es a su vez el parapeto exterior del Monte del Templo-Haram al Sharif), lo pusieron de manifiesto. El estallido de la Intifada al Aqsa, tal como lo denota su nombre, centraliza nuevamente el elemento religioso, presente en actitudes palestinas anti-israelíes, que a través de propaganda y hechos, a veces cobran un claro carácter anti-judío general, en términos de conflicto religioso.

La terminología de Hamás y Jihad Islámica resalta el elemento de "guerra de religión", al punto que se hace difícil diferenciar entre la parte 'nacional' y la parte 'religiosa' del conflicto. En este sentido, debemos mencionar la apreciación de Rodríguez Elizondo cuando se refiere a las "raíces abrahámicas" de Israel. Al señalar la importancia de la dimensión cultural religiosa, el autor mencionado aporta un elemento analítico que, sin dis- minuir el impacto de los factores modernizadores, presentes tanto entre israelíes como palestinos, dan al conflicto entre estas partes un substrato mucho más profundo y difícil de resolver, en términos políticos modernos ${ }^{4}$. Por otro lado, en términos de nacionalismo israelí, está claro que desde 1967, la centralidad del elemento religioso quedó establecida al declararse la "necesidad" de crear asentamientos en Cisjordania, a partir de las promesas bíblicas referentes a la Tierra Prometida. La actividad posterior de Gush Emunim -Bloque de Creyentes- y los grupos seguidores de la ideología extremista del Rabino Meir Kahana, son elementos que corroboran la tesis de que la confrontación israelí palestina es un conflicto nacional-religioso.

\section{La centralidad del elemento religioso quedó establecida cuando se declaró la "necesidad" de crear asentamientos a partir de las promesas bíblicas.}

\section{EL ASPECTO ISRAELÍ INTERNO DE LA INTIFADA}

Contribuyó en forma notoria a alimentar e intensificar los disturbios el que la policía israelí no estuviera preparada para

${ }^{3}$ A mi parecer, lo mejor que se ha escrito al respecto sigue siendo Emmanuel Sivan, Radical Islam: medieval theology and modern politics, New Haven, Conn., Yale University Press, 1985.

${ }^{4}$ José Rodríguez Elizondo, "Conflicto Israelí-Palestino: Estado de Situación", Revista Estudios Internacionales, $\mathrm{N}^{\mathrm{o}}$ 136, Santiago de Chile, octubre-diciembre 2001. 
contener a los manifestantes. Esto, en situaciones de peligro para sus agentes, la obligó a recurrir una y otra vez al uso de armas de fuego en los primeros días de la Intifada Armada. Las manifestaciones se extendieron rápidamente y pronto comenzaron a participar ciudadanos árabes-israelíes, apoyando a su connacionales - pero no conciudadanospalestinos. El resultado fue que los choques causaron la muerte de 13 jóvenes árabes-israelíes y la fractura entre los dos grandes grupos poblacionales en Israel se profundizó y agudizó.

\section{El renacimiento islámico ha sensibilizado al árabe-israelí en lo que respecta a los sacros lugares.}

Aquí también hay que tener en cuenta que más allá de los elementos nacionalistas palestinos, siempre presentes en la cultura árabe-israelí, el renacimiento islámico de la última década ha sensibilizado notoriamente al árabe-israelí en todo lo que respecta a los sacros lugares. Es así que el acceso y el monopolio de culto islámico en el Monte del Templo-Haram al Sharif son temas muy discutidos y de alta sensibilidad en el seno de la población árabe en Israel. El alto número de víctimas y la violencia de los enfrentamientos entre este sector y la policía, por los motivos ya citados -nacionales palestinos y religiosos islámicos, fuertemente entremezcladosno podían sino generar fuertes demandas políticas por parte del sector árabe-israelí. Si a esto se agregan las frustraciones que esta minoría ha acumulado desde el establecimiento de Israel como Estado soberano, en el que la población árabe es minoritaria y ocupa los estratos socioeconómicos más bajos, está claro que la explosión y sus resultados impactaron en forma violenta en el escenario político israelí.

Ante el clamor del sector árabe-israelí, las autoridades establecieron la Comisión Orr, encargada de clarificar los hechos que provocaron la muerte de las trece víctimas antes mencionadas. Esta Comisión, a la que se le atribuyeron facultades de investigación jurídica, es presidida por el juez Theodore Orr y sus miembros serían el conocido orientalista y exembajador de Israel en Jordania, profesor Shimon Shamir y el juez Sahal Jarah, de Nazareth, más tarde reemplazado por el juez Hashem Hatib ${ }^{5}$. Muchos expertos en Israel consideraron que el ahondamiento de la fractura árabe-judía en Israel misma es, quizás, el más grave resultado del estallido de la Intifada al Aqsa en septiembre-octubre del 2000.

La violenta represión de manifestantes 'árabes' -ciudadanos israelíes pero claramente identificados por sus orígenes socioculturales y aun nacionales como palestinos-que causó trece muertos entre éstos, creó una situación política peculiar en la que gran parte del voto árabe no participó en la elección israelí de febrero 2001 para Primer Ministro, en la que resulta ele-

${ }^{5}$ Para más detalles véase As'ad Ghanem, “A Year after the October Incidents: What has Changed”, Survey of the Arabs in Israel, 28, October 2001. 
gido Sharon. Esto se debió a que las víctimas mencionadas murieron en el período en que Israel era gobernado aún por el gobierno laborista de Barak. De aquí que mucho voto árabe se abstuviera y no votara nuevamente por Barak como candidato a la reelección y tampoco por Sharon, percibido como el candidato del nacionalismo anti-árabe. Estos hechos a su vez volvieron a centralizar el debate sobre la participación del sector árabe en la política israelí alrededor del tema de Israel como Estado judío y a la vez democrático, es decir, de todos sus ciudadanos, incluyendo la minoría árabe-israelí.

EL DESARROLLO DE LA VIOLENCIA Y EL ROL DE LOS MEDIOS DE COMUNICACIÓN

Los choques entre israelíes y palestinos se multiplicaron desde fines de septiembre del 2000, cuando se acuña el término Intifada al Aqsa, señalando así el comienzo de ésta con la visita de Sharon al álgido sitio sacro en Jerusalem.

Al principio, las manifestaciones palestinas adquieren la semblanza de protesta civil violenta, frente a la policía $\mathrm{y}$, especialmente, frente a tropas israelíes en Cisjordania y Gaza. La participación social es numerosa e intensa y destacan niños y jóvenes quienes con creciente intensidad apedrean a las tropas israelíes.

La respuesta israelí en general se hace a través del uso de gases lacrimógenos y, cuando esto se prueba insuficiente, mediante el uso de balas de goma, que pueden llegar a herir y hasta a matar.
En octubre del 2000, la cantidad de choques entre manifestantes palestinos y tropas israelíes aumentó en forma notoria, como también el nivel de violencia de los enfrentamientos. Éstos fueron degenerando en choques en que ambas partes comenzaron a usar armas de fuego. En esa época, las diferencias estructurales entre la Autoridad Palestina e Israel contribuyeron a exacerbar los enfrentamientos. Esta afirmación se refiere a la guerra propagandística emprendida en clave ideológica por diversos sectores políticos palestinos y que, ante una estructura gubernamental palestina débil, fue empujando a los medios de comunicación oficiales y privados no sólo a hacerse eco de las posiciones más extremas, sino a emprender una campaña anti-israelí demonizante.

\section{La Intifada al Aqsa se inicia con la visita de Sharón al álgido sitio sacro en Jerusalem.}

En el marco de esta campaña, rápidamente se dejó de diferenciar entre los diversos sectores en Israel y entre la sociedad y el gobierno de este país. El resultado de este tipo de manejo mediático fue el aumento de los choques entre grupos palestinos enardecidos y las tropas israelíes, no sólo por los hechos mismos, sino por la carga propagandística polarizante que emanaba de los medios de comunicación.

Aquí hay que recalcar otro punto importante en el desarrollo de la Intifada Armada o Intifada al Aqsa. Desde un principio la sucesión de eventos se desarrolló 
en la parte palestina como una rebelión de carácter popular, similar a la primera Intifada. Policía y tropas israelíes enfrentaban manifestaciones populares palestinas masivas. Cuando el nivel de choque se tornaba tal que la parte israelí comenzaba a usar balas de goma, se encontraban a menudo en la parte palestina algunos activistas políticos armados, o miembros de las fuerzas de seguridad palestinas, que abrían fuego con munición normal, sobre las tropas israelíes. Éstas a su vez, en grave inferioridad numérica de antemano, y de acuerdo a las órdenes de apertura de fuego, respondían con fuego. A veces el fuego israelí era abierto cuando soldados israelíes eran atacados con botellas incendiarias.

\section{Pocos se ajustaron a normas éticas claras sobre el reportaje de actos de violencia.}

En general, la imagen mítica del niño palestino lanzando una piedra, baleado a sabiendas por el soldado israelí modernamente pertrechado, es irreal. Este tipo de imágenes resultaron del tipo de reportaje que una y otra vez enfocó un hecho dramático y "telegénico", pero muy fuera de contexto. Más que reflejar en forma precisa, realista y contextual los eventos reales, podría afirmarse que los medios de comunicación masivos adaptaron la realidad a las necesidades mediáticas. Este fenómeno, en general, fue perjudicial para la parte israelí, pero cuando aumentaron los actos de terror masivos contra la sociedad israelí, perpetrados por extremistas palestinos, se repitió el mismo fenómeno en dirección contraria ${ }^{6}$.

Este tipo de reportajes naturalmente contribuyó a exacerbar una situación de por sí complicada y muy cargada de violencia. La descontextualización de los hechos contribuyó seriamente a los procesos de 'emocionalización' que comenzaron a sacudir a las opinión pública de ambas partes y la extremizó. Esto también se reflejó a nivel internacional, donde Israel fue perdiendo una guerra propagandística en la que la Autoridad Palestina logró posicionarse como "víctima absoluta" logrando achacar, en su rol de David, casi toda la responsabilidad por la violencia generada al Goliat israelí.

Puede afirmarse, sin atribuir responsabilidad directa por lo ocurrido a los medios de comunicación, que son pocos los que se ajustaron a normas éticas claras sobre el reportaje de actos de violencia. En lo principal, esto se debe a las necesidades y presiones de rating y comerciales de los medios de comunicación modernos y al envío de equipos que poco o nada sabían sobre el problema israelípalestino. A esto hay que agregar la influencia de las maquinarias propagandísticas, tanto palestina como israelí, sobre los medios de prensa tanto escrita como electrónica. Otro factor es el poco crítico consumo de noticias por parte del público internacional, para gran parte del cual

\footnotetext{
${ }^{6}$ Sobre este punto véase Gadi Wolsfeld, "The News Media and the Second Intifada. Some Initial
} Lessons", The Harvard International Journal of Press/Politics 6 (4), Fall 2001, pág. 113-115. 
el problema árabe israelí es otro "drama noticioso" para consumir ${ }^{7}$. Está claro que una prensa poco analítica, y quizás algo sensacionalista, contribuyó a potenciar los niveles de conflicto a través de su contribución "narrativa".

\section{Cada parte actuó dentro de los límites permitidos por sus estructuras, instituciones y nivel de legalidad.}

Una vez cruzada la barrera del fuego abierto entre las dos partes, la participación de elementos armados palestinos, oficiales y no oficiales, se convirtió en la norma de la Intifada Armada. La respuesta israelí, en su intento de contener los brotes de violencia palestina mediante el uso de la policía y el ejército, compone la tesis sobre las fricciones creadas estructuralmente por los niveles de institucionalización muy desparejos existentes entre la Autoridad Palestina e Israel. Cada parte actuó dentro de los límites que sus estructuras, instituciones y nivel de legalidad les permitieron. Es así que Israel envió a sus tropas a enfrentar la ira popular palestina, tratando de aislar a su población civil del conflicto. En el otro lado, habiendo estallado la revuelta popular, las instituciones armadas palestinas fueron prácticamente arrastra- das a participar como tales en la confrontación. Al suceder esto, el nivel de violencia subió notoriamente y los liderazgos políticos de ambas partes tuvieron qué decidir qué camino tomar.

La nueva fase del enfrentamiento, que ya lleva más de un año, fue lanzada por la introducción palestina del elemento suicida. Jóvenes palestinos, al principio sólo miembros de Hamás y Jihad Islámica, pero más adelante también de Tanzim, el brazo armado de al Fataj, comenzaron a atacar objetivos israelíes, en su mayoría civiles -transporte público, cafés, restaurantes, centros comerciales y hasta una sala de juegos de azar (cuya existencia en Israel es ilegal)- autodetonando la carga explosiva que portaban sobre el cuerpo. Esto llevó, a su vez, al lanzamiento de grandes operaciones militares israelíes, que implicaban la ocupación de los territorios controlados por la Autoridad Palestina y aun el sitio de Arafat en Ramala.

Nuevamente, ambas partes aceleraron a través de sus actos y, diría yo, su falta de política, la espiral de violencia, sin que ninguna lograra doblegar a la otra. Indudablemente, las organizaciones extremistas palestinas habían logrado desarrollar, a partir de tecnologías simplísimas y de bajo costo, una respuesta estratégica al poderío militar israelí, mediante el lanzamiento de suicidas contra grandes grupos civiles. Esto aumentó la presión militar

${ }^{7}$ Sobre los problemas de ética y profesionalismo periodístico en relación con el conflicto palestinoisraelí, véase Mario Sznajder, “A Draft Proposal for Israeli-Palestinian Security”, Is Oslo Alive?, Jerusalem, Konrad Adenauer Stifstung, Truman Institute, Palestinian Consultancy Group, 1998, pág. 19-24, en el que propuse, en noviembre de 1997, profesionalizar la manera en que la prensa escrita y electrónica relataba el conflicto palestino-israelí en sus fases violentas, para aminorar el fenómeno de exacerbamiento popular y demonización del enemigo, tan nocivos para el proceso de paz. 
israelí, lo cual produjo un deterioro más profundo de las condiciones de vida en Gaza y Cisjordania. Por otro lado, la sociedad israelí, sufriendo el impacto de los ataques suicidas y de la amenaza pendiente del incremento de éstos, sufrió también cambios negativos de carácter económico y social.

\section{LA DOBle FAZ DE ARAFAT}

Fue en este punto cuando Arafat cometió un error de carácter estratégico -en términos de los objetivos políticos palestinos a largo plazo- al liberar a los activistas de Hamás y Jihad Islámica en nombre de la unidad nacional palestina, potenciando la capacidad ofensiva y abriendo el camino a actos de terror antisraelíes que terminarían por debilitar a la Autoridad Palestina.

Quizás, frente a una crisis mayor, una de las características originales de Arafat se revelaba con mayor énfasis. Acostumbrado a muchos años de exilio, como jefe de lo que veía como el movimiento de liberación palestino, no le era fácil realizar la transición de líder guerrillero -o líder terrorista, dependiendo del ángulo del que se mirase- a nation-builder, es decir, constructor de la nación y del Estado nacional palestino. El segundo rol requería una visión legalista e institucionalizadora en la que intereses personales y políticos deberían ser sacrificados en pos del objetivo organizacional, para generar estabilidad y nuevas reglas de juego. El retorno a la violencia como vía de logros políticos hace pensar en esa dicotomía ${ }^{8}$.

\section{Para Arafat, la transición de líder guerrillero a constructor del Estado nacional palestino no era fácil.}

El hecho de liberar a los activistas extremistas islámicos ligados al terror, percibido en aquel momento como una contribución a la lucha palestina contra la ocupación israelí, era parte de la antigua táctica de Arafat. Ésta consistía, desde el punto de vista táctico, en aprovechar toda crisis para obtener ventajas políticas. En este sentido, el agudizar la violencia a través de la liberación de elementos extremistas y proclives al terror que poblaban las cárceles de la Autoridad Palestina, parecía ser un paso de avance para esa causa. Sin embargo, una lectura más profunda de la situación lleva inmediatamente a tres conclusiones parciales. La naturaleza táctica de esta medida era contradictoria con el objetivo estratégico declarado de Arafat, de establecer un Estado palestino independiente, a través de negociaciones con las potencias y con Israel. Este paso indicaba que Arafat se movía en una dirección que lo alejaba de la solución política. ${ }^{9}$

${ }^{8}$ Un examen biográfico serio de Arafat es el de Danny Rubinstein, The mystery of Arafat, South Royalton, Vermont, Steerforth Press, 1995.

${ }^{9}$ Sobre este punto, véase una interesante tesis en Yazid Sayigh, "Arafat and the Anatomy of Revolt", Survival, 43 (3), Autumn 2001, 47-60. Sayigh sostiene que las decisiones de Arafat en el otoño del 2000 se 
El segundo problema era de carácter interno. La popularidad de Arafat y su legitimidad política interna podían sufrir seriamente, tal como sucedió, al poder Hamás y Jihad Islámica actuar libremente y llevar adelante la tesis de la guerra total contra Israel, en términos de ataques terroristas.

Pero el tercer problema creado por Arafat con esta política era el peor. La libre actuación de los grupos extremistas, totalistas y terroristas, les permitiría, llegado el momento, tener la suficiente fuerza para impedir que se volviera a la mesa de negociaciones entre israelíes y palestinos. Si Arafat intenta hacerlo, sobre la base de los resultados de la confrontación, puede ser presentado por Hamás y Jihad Islámica como un traidor a su pueblo.

La dispersión de los núcleos terroristas y la pérdida de control palestino sobre éstos bien podrían, en caso de una confrontación palestina interna, llegar a constituirse en una amenaza real contra Arafat mismo.

El precio real de este error se vería con claridad en el futuro, cada vez que Arafat y sus seguidores intentasen reemprender el camino de las negociaciones, en la forma de actos de terror devastadores, que impedirían a ambas partes reunirse para negociar.
EL HUNDIMIENTO DE BARAK

El gobierno de Ehud Barak, aun adhiriendo a las tesis de Camp David como último recurso de propia supervivencia política, intentó negociar una salida del impasse violento.

\section{En caso de confrontación interna, la pérdida de control palestino sobre los núcleos terroristas podía convertirse en amenaza real contra el propio Arafat.}

En diciembre del 2000, tras concurrir a la reunión cumbre de Sharm al Sheikh, donde se estableció la Comisión Mitchell, para averiguar la naturaleza de los hechos que llevaron a la confrontación y a la de Washington, en la que se elaboraron propuestas para poner fin a la violencia y reanudar las negociaciones, israelíes y palestinos se reunieron en Taba, entre el $21 \mathrm{y}$ el 27 de enero del $2001^{10}$. Las negociaciones de Taba son la clara prueba de esta actitud. En éstas, se llega casi a fórmulas que podrían servir de base para un acuerdo final entre Israel y la Autoridad Palestina.

Sin embargo, ni el encuentro de Washington, ni las negociaciones de Taba lograron frenar la violencia. Por el contrario, los múltiples intentos de establecer un cese de fuego fracasaron uno tras otro.

encuentran entre los más grandes errores estratégicos de su larga carrera política, sólo comparables con las trágicas decisiones de enfrentar a los sirios en Líbano, en 1976, y de apoyar a Saddam Hussein en 1990.

10 "The Israeli Palestinian Negotiations", http://www.israel.org/mfa 
La Intifada Armada fue adquiriendo otras dimensiones. Los caminos transitados por habitantes de los asentamientos israelíes en Cisjordania y Gaza se convirtieron en escenarios de atentados contra éstos. Los palestinos recurrieron a francotiradores, cargas explosivas a la vera de los caminos, emboscadas contra el ejército y civiles, actos de terror contra la población civil en las ciudades de Israel (realizados en gran parte por suicidas convencidos, en términos islámicos extremistas y mesiánicos), hasta llegar al uso de morteros y misiles de corto alcance contra asentamientos israelíes e incluso Jerusalem.

Entre los hechos más graves están los continuos tiroteos entre Giloh y Beit Jalla. Giloh, uno de los barrios de Jerusalem, en la parte sur de la ciudad, colinda con Beit Jalla, pequeña ciudad palestina vecina a Belén. Frecuentes disparos de disidentes palestinos desde ésta última produjeron fuertes respuestas israelíes, incluyendo en más de una oportunidad la reocupación de Beit Jalla por parte de Israel.

La reocupación israelí de áreas controladas por la Autoridad Palestina se ha producido ya en varias oportunidades y es una clara muestra de la gravedad de la situación, ya que de convertirse en un fenómeno continuo podría producirse el desmoronamiento de la Autoridad Palestina. Hasta ahora, la reocupación se produce como respuesta a ataques o actos de terror palestinos y es por períodos limita- dos, tras los cuales, las tropas israelíes se retiran.

El deterioro de la seguridad interna en Israel y en los asentamientos israelíes en Cisjordania y Gaza, así como el fracaso de todo intento de cese del fuego y arreglo político, condujeron a las elecciones israelíes para Primer Ministro, de febrero del 2001, en las que Ariel Sharon venció a Ehud Barak por abrumadora mayoría ${ }^{11}$.

\section{La preocupación israelí de áreas controladas por la Autoridad Palestina podría conducir al desmoronamiento de ésta.}

Ehud Barak fue citado por la Comisión Orr para que aclarase su responsabilidad, como Primer Ministro, por los sucesos violentos de fines de septiembre del 2000, en los que trece árabes-israelíes perdieron la vida. La Comisión, que posee facultades judiciales, puede llegar a decidir sobre la responsabilidad de Barak y otras autoridades, políticas y administrativas, y recomendar a la fiscalía general que se someta a juicio a aquellos que en sus declaraciones no lograron convencerla de que actuaron dentro de los marcos legales, haciendo todo lo posible para evitar la pérdida de vidas humanas.

${ }^{11}$ El resultado de la elección para Primer Ministro de Israel, el 6 de Febrero del 2001, fue: 62.6\% del voto a favor de Ariel Sharon; 37.2\% a favor de Ehud Barak. "Israel Elections 2001", http://www.cnn.com/ SPECIALS/2000/Israeli. 


\section{SHARON: ¿HALCÓN IDEOLÓGICO Y POLÍTICO PRAGMÁTICO?}

Gran parte de los electores que votaron por Sharon eligieron al severo general que impuso orden con mano dura en la Franja de Gaza en los años setenta, o a un duro nacionalista que reprimiría la Intifada Armada y devolvería la calma a la sociedad israelí. Otros vieron un Sharon más político y más moderado que, con años de experiencia, había aprendido las lecciones de la Guerra del Líbano y la necesidad de compromisos políticos.

Entre estas dos imágenes bastante polarizadas se mueve Ariel Sharon hasta el día de hoy, transmitiendo, por un lado, mensajes políticos proclives al compromiso si las condiciones se dan y, por otro, asestando duros golpes a la contraparte palestina cuando ésta recurre a la violencia. Esta doble faz explica también la supervivencia de la amplia coalición de gobierno que Sharon formó, frente a la insistencia pública en la necesidad de unión nacional para enfrentar la crisis. Se estableció rápidamente un gobierno de unidad nacional y Ariel Sharon declaró que no negociaría con los palestinos hasta que no se lograra calma total, es decir, un cese del fuego efectivo sin ninguna clase de actos terroristas o violentos.

El gobierno de unidad nacional, con la participación del Partido Laborista y Shimon Peres como canciller, otorgaba a Sharon una amplia capacidad de maniobra política y apoyo popular que, pese a las vicisitudes de la Intifada Armada y la campaña terrorista anti-israelí, se mantuvo hasta ahora.

\section{El gobierno de unidad nacional daba \\ a Sharon amplia capacidad de maniobra política y apoyo popular.}

Durante el año y medio que Sharon lleva en el gobierno ha probado sus habilidades tácticas en varios planos. Ha logrado someter y debilitar al Partido Laborista de tal manera que, de acuerdo con las encuestas de opinión pública, si se realizaran elecciones en este período, el Partido Laborista perdería gran parte de su caudal electoral. Sharon, pese a la crisis de seguridad y a la crisis económica que la acompaña, mantiene un alto nivel de popularidad. También logró reforzar las relaciones con Estados Unidos y consiguió apoyo continuo por parte del presidente Bush a sus políticas de represalia frente al terror y mano dura frente a la Autoridad Palestina. Bush también aceptó la tesis de Sharon de que siendo imposible lograr un acuerdo con Arafat, los palestinos deben efectuar profundas reformas y generar un liderazgo más creíble.

Más allá de postergar a un futuro lejano el apoyo de su gobierno al establecimiento de un Estado palestino -mientras que Bush anunció que es la política de Estados Unidos conducir a la creación de un Estado palestino, tras la pacificación de la zona y en el término de tres añosSharon no parece tener un plan estratégico-político discernible. Esto crea graves problemas a nivel internacional, no sólo con el entorno de países árabes, interesados en calmar la zona y encarrilar el en- 
frentamiento hacia una solución política, temiendo que el desborde de la violencia termine haciendo estallar una guerra general en el Medio Oriente, sino también creando efervescencia política interna en Egipto, Jordania y Arabia Saudita. Es decir, la política de Sharon es vista como un fuerte elemento de desestabilización de todo el Medio Oriente.

Desde el punto de vista interno y pese a que el número de víctimas de la Intifada Armada ha crecido notoriamente -tanto en términos absolutos como porcentuales- la popularidad de Sharon y su gobierno de unidad nacional se ha mantenido en un alto nivel desde que asumió en marzo del 2001. Los niveles de popularidad y apoyo al gobierno de Sharon varían hasta un máximo de $71 \%$. Esto se explica por la polarización que la crisis produce dentro de Israel, por un lado, y por otro, por la desconfianza pública israelí en la contraparte palestina, resultado directo del creciente espiral de violencia terrorista ${ }^{12}$.

Otro punto que debe señalarse es el apoyo expresado por Sharon y su gobierno a las políticas antiterroristas de Estados Unidos en general y, en particular, a la intención de este país de atacar a Irak con el objetivo de derribar a Saadam Hussein. En este sentido, Sharon personalmente, y también su gobierno, no sólo han logrado evitar una confrontación política entre Israel y Estados Unidos, sino que han conseguido que el presidente Bush apoye a las políticas 'duras' antipalestinas.

\section{El INFORME MitChELL}

El informe, presentado el 21 de mayo de 2001 por el ex-senador norteamericano George Mitchell, que ya había logrado grandes éxitos al negociar el proceso de pacificación de Irlanda del Norte, trazó los parámetros de pacificación en el conflicto israelí-palestino y fue aceptado, en principio, por ambas partes.

Una de las conclusiones preliminares de esta comisión fue que, pese a que la visita de Sharon al Monte del TemploHaram al Sharif había sido mal coordinada y agendada, no era ésta la causa directa de la confrontación entre israelíes y palestinos.

\section{El informe Mitchell trazó los parámetros de pacificación en el conflicto y fue aceptado, en principio, por ambas partes.}

Mitchell pedía a ambas partes cesar el fuego y hacer todos los esfuerzos para pacificar la región. Asimismo, sostenía que deberían retornar a las negociaciones y que Israel debería levantar todo bloqueo y restricciones económicas impuestas a la Autoridad Palestina y a la población de ésta y también congelar el crecimiento de los asentamientos en Cisjordania y Gaza.

A la Autoridad Palestina se le exigía controlar todo acto de violencia antisraelí

${ }^{12}$ Para datos precisos sobre estos temas, véase Asher Arian, Israeli Public Opinion on National Security 2002, Tel Aviv, Jaffee Center for Strategic Studies, 2002, pág. 13 y otras.. 
y a Israel, el cese del uso de su fuerza militar contra la Autoridad Palestina. La comisión también recomendó la aplicación de medidas de reconstrucción de la confianza mutua entre las partes en conflicto $^{13}$.

De aquí en adelante, los intentos de establecer un cese del fuego entre las partes fracasarían, frente a la exigencia israelí de lograr al menos siete días de completa calma antes de volver a las negociaciones políticas. La parte palestina continuaría argumentando que hace cuanto está de su parte por controlar a los elementos díscolos en su territorio, pero no lo logra totalmente y que hay que proceder a negociar en forma política a partir de la reducción de la violencia y no de su desaparición total.

Varios hechos complicaron la situación. La falta de control de la seguridad en la parte palestina llevó a que la misma base de poder de Arafat, el movimiento al Fataj, comenzara a desarticularse. El brazo armado de Fataj, Tanzim, bajo el mando de Marwan Bargouti, personaje que en el pasado era visto como muy cercano a Arafat, se convirtió en uno de los actores centrales de la violencia palestina. Esto llegó al punto en que activistas del Tanzim realizan ataques dentro de Israel en cooperación directa con activistas del Jihad Islámico y Hamás. Pareciera que
Arafat hubiera perdido el control sobre parte de sus más fieles seguidores. En más de una ocasión, frente a los llamados de Arafat al cese de fuego, Bargouti preconiza la necesidad de continuar luchando en la Intifada para liberarse de la ocupación israelí, aunque al final acató la orden de Arafat de cesar el fuego ${ }^{14}$.

Aquí nos encontramos frente a otro fenómeno político manifiesto, que la Intifada Armada realzó. Desde 1994, con el retorno de Arafat y la antigua generación de líderes de al Fataj y la OLP de Túnez y el establecimiento de la Autonomía Palestina en Gaza y Jericó, la lucha política interna en las filas palestinas nunca cesó. Peor, no se trataba sólo de la confrontación entre las diversas corrientes e ideologías políticas, sino también entre la 'antigua elite' encabezada por el propio Arafat, y la nueva generación de palestinos que había liderado la Primera Intifada y creado las condiciones conducentes a los Acuerdos de Oslo. Es esta aguerrida generación, a la que pertenecen Bargouti y muchos otros, y así como los líderes de Hamás y Jihad Islámica, la que se torna activista y predica la tesis que ve en la Intifada Armada la etapa final de la guerra de liberación palestina. El choque generacional sale a luz claramente en el desafío político que enfrenta Arafat dentro de las propias filas de al Fataj ${ }^{15}$.

13 “The Mitchell Committee Report", http://www.cnn.com/2001/WORLD/meast/05/21.

${ }^{14}$ Marwan Bargouti fue arrestado en Ramala por el ejército israelí, en el marco de la Operación Escudo Defensivo. Bargouti ha sido sometido a juicio civil en Israel, acusado de instigar y organizar ataques terroristas en los que israelíes fueron asesinados. El proceso se ha transformado en un juicio político en el que Bargouti debate, en términos políticos, las razones palestinas del conflicto.

${ }^{15}$ Khalil Shikaki, "La Vieja y la Joven Guardias: la Autoridad Palestina y el proceso de paz en la 


\section{Arafat ha ido perdiendo autoridad y legitimidad.}

Arafat ha ido perdiendo autoridad y legitimidad. En el plano internacional, las acusaciones que contra éste ha dirigido el presidente Bush han aminorado su posición e influencia. El gobierno israelí simplemente descartó a Arafat como posible interlocutor. Pero el problema principal es un claro resultado de la doble faz de Arafat. El haber usado canales políticos y violentos en forma alternativa ha alejado a la sociedad palestina de su principal objetivo estratégico: el establecimiento de un Estado palestino. En vez de haberse fortalecido, la Autoridad Palestina se ha debilitado. Una serie de milicias armadas locales amenazan con "somalizar" -transformar en Somalia- a la Autoridad Palestina. El debilitamiento económico también contribuye al desarrollo de un fenómeno de anomia social en el cual lo que sobrevive de la Autoridad Palestina se debe a que aún llegan dineros extranjeros -de países árabes y la Unión Europea- para pagar sueldos a quienes dependen del fisco (empleados públicos en las áreas de educación, salud, municipalidades y policía). Pero la legitimidad y confianza pública se han perdido y si Arafat logra ciertos niveles de popularidad interna, gracias a actos violentos contra Israel -de resistencia, libe- ración u otra naturaleza- esta popularidad es efímera, mientras que el proceso de desinstitucionalización y anomia son a largo plazo $^{16}$.

En esta situación, creada parcialmente por las propias políticas palestinas, el dilema de Arafat en la Intifada Armada es profundo e inmediato. Por un lado, el reprimir a Hamás, Jihad Islámica y aun al Tanzim y otros elementos 'combativos' y terroristas que generan violencia, puede desencadenar una guerra civil palestina. Por otro, el no hacerlo, lleva a la confrontación directa con Israel.

\section{¿TERror local, TERror INTERNACIONAL?}

Los sucesos del 11 de septiembre del 2001 en Nueva York y Washington ahondaron los problemas en el campo palestino $y$, en cierto sentido, también en el lado israelí.

El hecho de que Arafat se alineara inmediatamente con el lado norteamericano respondía no sólo a su lectura de las fuerzas e intereses en juego, sino también a la lógica de la línea negociadora que había adoptado durante la década de los noventa. Aunque en la Intifada Armada Arafat había jugado un rol por demás ambiguo, está claro que uno de sus obje-

encrucijada", Revista de Estudios Internacionales, № 137, Santiago de Chile, abril-junio 2002. Shikali interpreta la lucha interna palestina como uno de los principales factores de polarización de la Intifada.

${ }^{16}$ Estos puntos fueron acentuados en la exposición del Profesor Yezid Sayigh, "Israel and Palestine - What future?", que se llevó a cabo en el marco de los seminarios de la Universidad de Medio Oriente del Instituto Truman de la Universidad Hebrea de Jerusalem, en ésta, el 10 de julio del 2002. 
tivos estratégicos era acercarse a los Estados Unidos para neutralizar lo que entre los palestinos y el mundo árabe en general se percibe como el sesgo norteamericano constante en favor de Israel.

Para la guardia joven palestina que dirigía el enfrentamiento en la Intifada y para parte de los sectores populares palestinos, muy castigados por meses de cierre fronterizo israelí, que había generado fuertes presiones económicas y sociales en Cisjordania y Gaza, así como para un gran número de víctimas, entre muertos y heridos, el odio antiisraelí y antinorteamericano es casi natural. De ahí que las muestras de alegría frente al terrorismo de Osama Bin Laden y Al Qaeda en Estados Unidos fueran un resultado más o menos espontáneo. Para los grupos extremistas radicales, estos hechos fueron vistos como una fuente de inspiración y un aliento a proseguir con la línea violenta.

\section{Junto con la creciente ola terrorista, se agudiza en Israel la discusión sobre la presión que puede ejercerse sobre Arafat.}

Por otro lado, los sectores políticos vecinos a Arafat hicieron todo lo posible para disociarse, a los ojos de los Estados Unidos y de occidente, del terrorismo islámico extremista.
En Israel las interpretaciones fueron varias. Algunas visiones simples quisieron creer que el 11-S era el día en que el mundo comenzaría a identificar a Israel como víctima del mismo terror que había golpeado en Nueva York y Washington. En el gobierno se temió que el presidente Bush exigiera de Israel precios políticos inaceptables frente a la Autoridad Palestina, para pacificar esta región y quitar a Osama Bin Laden todo pretexto teológico a su argumentación contra occidente, aislándolo así de todo apoyo por parte del mundo islámico y permitiendo operar libremente contra él. También, junto con la crecientes ola terrorista, se agudiza en Israel la discusión sobre las medidas de presión que pueden ejercerse sobre Arafat. A la discusión sobre el cierre de los territorios controlados por la Autoridad Palestina y sus efectos como 'castigo colectivo', ya hace meses se había agregado la discusión sobre la política israelí de ataques mortales directos a los responsables operacionales de los actos terroristas anti-israelíes. La efectividad de ésta política, medida en términos militares, era puesta en duda no sólo por el terror cada vez mayor, sino especialmente por la creciente popularidad de Hamás en las ciudades de Cisjordania y Gaza. Aquí se ponía en juego la antigua tesis sobre si Hamás reemplazaría a Arafat si éste cae y se desmorona la Autoridad Palestina ${ }^{17}$.

${ }^{17}$ Aquí se revivía la antigua tesis de Shikaki y otros, y también de la izquierda en Israel. Por ejemplo, ver Idem, "The politics of paralysis II - Peace now or Hamas later", Foreign Affairs 77 (4), JulyAugust 1998. 


\section{Conclusiones}

El dilema de Sharon no es simple. Los grupos nacionalistas, dentro y fuera del gobierno, ejercen fuertes presiones y amenazan con retirar su apoyo a la coalición. Esto podría llevar a una elección temprana, en una situación de profunda crisis de seguridad y económica. En este tipo de escenario, la retórica de Benjamín Netanyahu podría ser tan perjudicial para Sharon, que éste correría el riesgo de perder la jefatura de su partido, el Likud, y la jefatura del gobierno.

\section{El Primer Ministro israelí es más proclive a atender las exigencias de la derecha nacionalista.}

Por otro lado, la penosa situación en que se encuentra el dividido Partido Laborista permite a Sharon adoptar posiciones duras frente a los palestinos, sin que el laborismo se retire del gobierno. De aquí que el Primer Ministro israelí, debido a la circunstancia política interna, se haya tornado más proclive a satisfacer las exigencias de la derecha nacionalista que las del laborismo, ya que es la derecha más capaz que el laborismo de retirarse del gobierno y hacerlo caer. Por otro lado, la presión internacional funciona como elemento moderador y gran parte de las represalias israelíes, efectuadas como respuesta a actos de terror palestinos, son de alto impacto simbólico y materialmente devastadoras, pero sin tocar personalmente a los líderes políticos palestinos -con la excepción de Bargouti-ni intentar desmoronar totalmente a la Autoridad Palestina.

Los términos básicos de análisis, presentados a lo largo de este trabajo, son los que condicionan la situación actual, esto es, la relación entre política exterior y política interna, tanto en el caso israelí como en el palestino; el nivel de estructuración e institucionalización de cada una las partes, no sólo como factor de negociación sino también de control de la violencia; el manejo político de los líderes de ambas partes y sus reacciones frente a un cuadro internacional muy afectado por los sucesos del 11-S. Estos tres ejes, presentados en forma entrecruzada e interactiva, explican cómo se llegó a la situación actual y cuáles son actualmente los parámetros definitorios del conflicto palestino-israelí. Es por conducto de estos que podemos analizar los diversos factores que influyen en el proceso: la confrontación vista en términos de guerra de religión; la actuación de los árabes israelíes como factor político interno; el rol de los medios de comunicación respecto del desarrollo de la violencia; las actuaciones de Arafat, Barak y Sharon; y el plano internacional, mediante el Informe Mitchell y las secuelas de los eventos del 11 de septiembre del 2001.

La posible confrontación entre Iraq y Estados Unidos probablemente implicaría a Israel. Si Estados Unidos atacan a Iraq, es probable que el gobierno de Saddam Hussein lance un ataque contra Israel con el objeto de crear un frente árabe general contra Estados Unidos, al desencadenar una reacción israelí contra Iraq. 
En una situación de este tipo es probable descarrilado el proceso de paz que se produzca una desestabilización ge- palestino-israelí y lo han convertido en neral de todo el Medio Oriente con gra- una de las más violentas y peligrosas ves consecuencias para el conflicto crisis de los últimos años, cuyas palestino-israelí también. implicaciones revisten importancia no

Sin poder cubrir todos los elementos de tan intrincado conflicto hemos intentado aclarar las causas y factores que han sólo para los actores del conflicto, sino para todo el Medio Oriente y, quizás, mucho más allá de éste. 